\title{
CRIME AMBIENTAL E SUAS CONSEQUÊNCIAS NA RESPONSABILIDADE CIVIL POR DANO AO MEIO AMBIENTE
}

\author{
ENVIRONMENTAL CRIME AND ITS CONSEQUENCES ON \\ CIVIL LIABILITY FOR ENVIRONMENTAL DAMAGE
}

\author{
FERNANDO MARQUES KHADDOUR ${ }^{1}$ \\ ELCIO NACUR REZENDE ${ }^{2}$
}

\begin{abstract}
RESUMO: Devido ao desenvolvimento da humanidade, desenvolvimento este que se deu através da utilização e extração de recursos naturais, de forma ininterrupta, e desencadeando com a produção industrial de bens, tem levado o homem a conscientização da importância da preservação do meio ambiente para sua própria sobrevivência, (modernidade reflexiva), acarretando a necessidade de uma construção jurídica, (responsabilização), como mecanismos para o controle e proteção a esse bem tão caro, homenageando-se assim os princípios da precaução, prevenção e poluidor pagador consagrados pelo direito ambiental. Com efeito, o crime ambiental tem a responsabilidade penal como um desses meios de controle, como, também, a responsabilidade civil, os quais são aplicados independentemente na coerção, porém se completam no Direito Ambiental para se atingir um objetivo maior, um meio ambiente equilibrado e sustentável. Trata-se de um verdadeiro desafio pois está a se falar de um direito difuso, já que o Direito Penal, através de sua construção dogmática tradicional, encontra dificuldade no que tange a proteção a esse direito magnânimo, utilizando-se, historicamente, do Direito Administrativo e do Direito Civil como instrumentos de coerção e de responsabilização do degradador.
\end{abstract}

PALAVRAS-CHAVE: Responsabilidade; Subjetiva; Objetiva; Direito; Penal; Cível.

ABSTRACT: Due to the development of humanity, this development that occurred through the use and extraction of natural resources, without interruption, and triggering with the industrial production of goods, has led man to awareness of the importance of preserving the environment for survival, (reflexive modernity), causing the need for a legal arrangement, (accountability), as mechanisms for the

Artigo recebido em 23.04.2015. Pareceres emitidos em 09.06.2015, 19.10.2015 e 30.11.2015.

Artigo aceito para publicação em 16.01.2016.

${ }^{1}$ Bacharel em Direito. Advogado Militante. Especialista em Direito Criminal (pós latu sensu). Mestrando em Direito Ambiental na Escola Superior Dom Helder Câmara, Belo Horizonte/MG. fkhaddour@yahoo.com.br

${ }^{2}$ Mestre e Doutor em Direito. Coordenador e Professor do Programa de Pós-graduação em Direito da Escola Superior Dom Helder Câmara, Belo Horizonte/MG. elcionrezende@yahoo.com.br 
control and protection of this well as expensive, if thus honoring the principles of precaution, prevention and polluter pays enshrined in environmental law. Indeed, the environmental crime has criminal liability as a means of control of these, as also the liability, which are applied independently on coercion, but complement the Environmental Law to achieve a higher goal, a balanced environment and sustainable. This consists of a challenge as it is to talk of a diffuse right, since the Criminal Law, through its traditional dogmatic construction, finds it difficult when it comes to protection of this magnanimous right, using historically Law Administrative and Civil Law as instruments of coercion and accountability of degrading.

KEYWORDS: Responsibility; Subjective; Objective; Law; Criminal; Civil.

SUMÁRIO: Introdução; 1. Os Motivos da Responsabilização pelos Danos causados ao Meio Ambiente; 2 . Crime Ambiental, Culpabilidade e Responsabilidade Penal; 3. A Aplicação da Responsabilidade Civil nos casos de Dano Ambiental; 4. Relação entre o Crime Ambiental e a Responsabilidade Civil;

Conclusão; Referências.

SUMMARY: Introduction; 1 . The Reasons of Accountability for Damage caused to the Environment; 2. Environmental Crime, Culpability and Criminal Liability; 3. The Application of Civil Liability in Cases of Environmental Damage; 4. Relationship between the Environmental Crime and Civil Responsibility; Conclusion; References.

\section{INTRODUÇÃO}

O presente artigo tem por finalidade analisar as consequências do crime ambiental na responsabilidade civil pelo dano causado ao meio ambiente. Para se chegar a esse objetivo, se faz necessária a observação de alguns pontos importantes, tais como: o motivo da responsabilização em matéria ambiental; a responsabilidade penal, que passa pela culpabilidade; a independência dos ramos do direto na aplicação das sanções e a dependência desses mesmos ramos do direito para realização do objetivo mais importante, que é foco do Direito Ambiental, (qualidade de vida com sustentabilidade ambiental), previsto na Constituição Federal de 1988, art. 225, chegando-se ao final a ligação entre crime ambiental e responsabilidade civil por dano e a funcionalidade do direito na tentativa da construção de um País, quem sabe de um mundo, ecologicamente equilibrado para a atual e as futuras gerações.

\section{OS MOTIVOS DA RESPONSABILIZAÇÃO PELOS DANOS CAUSADOS AO MEIO AMBIENTE}

A questão aqui pretendida passa inicialmente sobre a ótica do dano, especificamente no meio ambiente, denominado dano ambiental. Segundo se verifica na obra de Annelise Monteiro Steigleder, o biólogo alemão Haeckel estudando espécies animais, orgânicos e inorgânicos, em 1866, deu origem a Ecologia, sendo tal nome proveniente da palavra grega oikos (casa), somada a denominação de ciência, estudo, chegando a denominação ecologia, (ciência da casa) ${ }^{3}$.

\footnotetext{
${ }^{3}$ STEINGLEDER, 2011, p. 17.
} 
Certo é que a Ecologia, que teve um início desvinculado do homem o incluiu devido à necessidade de produção e desenvolvimento desse mesmo homem, feita através da utilização e extração de recursos naturais, fazendo com que o homem passasse a ser suscetível "de determinar o discurso dogmático do direito ambiental em geral e o regime jurídico da responsabilidade por danos ecológicos". ${ }^{4}$

Assim, a utilização desses recursos naturais de forma ininterrupta e crescente, durante longos períodos, passou a impedir a autorregulação e automanutenção do organismo natural, sem falar nos danos que impedem instantaneamente a cura natural por sua agressividade, (ex: destruição de monumentos históricos), causando a destruição permanente de certos sistemas, o que é chamado de impacto ambiental, o choque que altera o ambiente, sendo mais importante para o estudo quando traz malefícios.

Sem entrar na seara do antropocentrismo, para determinar a valoração do meio ambiente natural, ou seja, se sua importância basta em si mesmo ou está relacionada às necessidades humanas e exclusivamente humanas, criou-se o instituto da responsabilização para regulação e controle, conforme exposto, sendo deixado de lado a discussão relativa a questão etimológica da palavra responsabilidade, porém, importante ressalta, conforme fez Fiorillo, para deixar clara e sem dúvida a importância, que;

A Constituição Federal de 1988 consagrou de forma nova e importante a existência de um bem que não possui características de bem público e, muitos menos, privado, voltando à realidade do século XXI, das sociedades de massa, caracterizada por um crescimento desordenado e brutal avanço tecnológico. ${ }^{5}$

Assim, esta responsabilização se dá na seara cível através da obrigação de fazer e não fazer ou pagamento em dinheiro; na seara administrativa uma sanção administrativa (multa, suspensão de licença, etc), e na seara penal também uma sanção, porém com outro viés, em forma de pena, através de uma óptica garantista para restabelecer a ordem social, "criando um estigma".

Assim, toda agressão ao meio ambiente é passível de responsabilização em qualquer das searas jurídicas de forma independente, ou seja, a responsabilidade penal, civil e administrativa são autônomas, independem entre si, uma ação ou omissão pode ser tutelada pelas três esferas jurídicas com três consequências distintas, (art. 225 , § $3^{\circ}$ da CF/88 e art. $3^{\circ}$ da Lei 9.605/98), sendo que, se o ato praticado contra o meio ambiente estiver previamente tipificado como crime ambiental, (princípio da legalidade), será tutelado pelo Direito Penal, sem prejuízo de aplicação dos outros ramos do direito.

\footnotetext{
${ }^{4}$ STEINGLEDER, 2011, p. 17.

${ }^{5}$ FIORILLO, 2014, p. 47.
} 
Verificando o Livro Crimes Ambientais Comentários a Lei 9.605/98, Ana Maria Moreira Marchesan e Sílvia Cappelli ${ }^{6}$ informam na introdução que:

A evolução tecnológica empurrou a sociedade brasileira representada por suas instâncias político-jurídicas a buscarem, também na esfera criminal, respostas para a grave crise ambiental, sociedade que se constrói sobre o paradigma da Sociedade de Risco, conforme a hipótese formulada por Ulrich Beck, que afirma: o conceito de sociedade de risco designa um estágio da modernidade em que começam a tomar corpo as ameaças produzidas até então no caminho da sociedade industrial.

O processo de modernização volta-se para si mesmo como tema e problema através da reflexividade, ou seja, passa a existir uma constatação, certamente pelo homem, da crise ambiental causada por sua produção, tendo em vista o fato de sua forma de organização, na maioria das vezes desordenada, suas indústrias, as condições tecnológicas, sem falar na gestão econômica da sociedade, estando todos esses fatores em conflito com a qualidade de vida desse mesmo homem ${ }^{7}$, qualidade de vida essa necessária à vida humana que foi declarada na Conferência das Nações Unidas em Estocolmo em 1972 e está estampada no caput do art. 225 da Constituição Federal de 1988.

Nesse sentido apontou Ulrich Beck quando escreveu sobre a distribuição de riqueza e de risco e sua lógica:

Na modernidade tardia, a produção social de riqueza é acompanhada sistematicamente pela produção social de risco. Consequentemente, aos problemas e conflitos distributivos da sociedade da escassez sobrepõem-se os problemas e conflitos surgidos a partir da produção, definição e distribuição de riscos científico-tecnologicamente produzidos ${ }^{8}$.

Assim a responsabilidade penal aparece como uma das formas de responsabilização para tentar regular a (in)sustentabilidade ambiental percebida por essa mesma sociedade que Beck chama de modernidade reflexiva ou modernidade tardia ${ }^{9}$, e amplamente divulgada em várias obras como por exemplo José Affonso Leme Machado ${ }^{10}$, que informa o seguinte:

A noção de sustentabilidade funda-se em pelo menos dois critérios: primeiro, as ações humanas passam a ser analisadas quanto à incidência de seus efeitos diante do tempo cronológico, pois esses efeitos são estudados no presente e no futuro; segundo, ao se procurar fazer um

\footnotetext{
${ }^{6}$ MARCHESAN, 2013.

${ }^{7}$ LEITE, 2014, p. 27.

${ }^{8}$ BECK, 2011, p. 23

${ }^{9}$ MARCHESAN, 2013, p. 14

${ }^{10}$ MACHADO, 2015, p. 59.
} 
prognóstico do futuro, haverá de ser pesquisado que efeitos continuarão e quais as consequências de sua duração.

A fim de atingir os objetivos constitucionais, é clara a importância do Direito Penal, como os outros ramos do Direito também o são, na regulação das condutas, que afetam o meio ambiente, sendo clara sua aplicabilidade diante da pessoa física, já que culturalmente a aplicação da pena se subsume em prisão. Ocorre que tratando-se de Direito Ambiental, ou dano ao meio ambiente, direito difuso, a penalização ou jus puniendi se aplica também a pessoa jurídica, ou seja, a responsabilização criminal da pessoa jurídica tem previsão legal, (§ $3^{\circ}$ do art. 225 da Constituição Federal de 1988 e art. $3^{\circ}$ da Lei 9.605/98), dispositivos que são aplicados na prática através do judiciário. Ocorre que a pessoa jurídica não pode ser presa, pelo menos nos moldes conhecidos até hoje, denominado como cárcere. Como se não fosse o suficiente, conforme explica Luiz Gustavo Gonçalves Ribeiro e Diógines Baleeiro Neto, em um artigo intitulado "Medidas Despenalizadoras e Proteção ao Meio Ambiente", o Direito Penal passa por uma real crise no que se refere a sua aplicabilidade, pois vejamos:

A evidente situação de crise vivida pelo Direito Penal, caracterizada pelo questionamento de sua eficácia por um significativo número de teóricos, torna impositiva a busca de alternativas à pena de prisão, com vistas ao resgate da legitimidade do sistema. Nesse contexto, a par das teorias abolicionistas e minimalistas, surgem correntes mais moderadas, que pugnam pela despenalização como possível resposta aos sintomas da crise, de sorte a reforçar a legitimação do Direito Penal como sistema protetor de bens jurídicos, ao tempo em que reduz a possibilidade de sua aplicação a condutas menos lesivas a tais bens. No Brasil, tal movimento ganhou corpo após a Constituição de 1988 e, sobre tudo, com a edição da Lei no 9.099/95, que, além de criar os Juizados Especiais Criminais, instituiu e disciplinou em nosso Direito as medidas despenalizadoras, a saber: composição civil, transação penal e suspensão condicional do processo.

Assim, havendo uma responsabilização cível, sem falar na sanção administrativa, haverá o questionamento de uma aplicabilidade do Direito Penal e sua possibilidade ou necessidade, pois para Claus Roxin, por exemplo, "faz-se necessário estabelecer qual a finalidade do Estado, já que, como se afirmou em oportunidade diversas, o fim da pena é o próprio objetivo do Direito Penal, e decorrentemente do estado"11.

Importante observar também, conforme já exposto, que a responsabilização criminal é subjetiva, enquanto a responsabilização cível é objetiva, inclusive sendo aplicada pelo STJ a responsabilização objetiva com base na teoria do risco integral. (REsp 1374284 / MG), como será visto posteriormente.

\footnotetext{
${ }^{11}$ HIRECHE, 2004, p. 75.
} 


\section{CRIME AMBIENTAL, CULPABILIDADE E RESPONSABILIDADE PENAL}

Segundo a doutrina, "Direito Penal é o conjunto de normas jurídicas que regulam o poder punitivo do Estado, tendo em vista os fatos de natureza criminal e as medidas aplicáveis a quem os pratica", tratando-se de uma visão garantista ${ }^{12}$. Francisco de Assis Toledo trás em sua obra uma definição sobre Direito Penal que sintetiza muito bem a visão cultural que se tem sobre este ramo:

Quando se fala em Direito Penal pensa-se logo em fatos humanos classificados como delitos; pensa-se, igualmente, nos responsáveis por esse fato - os criminosos - e, ainda, na especial forma de conseqüência jurídica que lhes estão reservadas - a pena criminal e a medida de segurança.

Sob esse ângulo, o Direito Penal é realmente aquela parte do ordenamento jurídico que estabelece e define o fato-crime, dispõe sobre quem deva por ele responder e, por fim, fixa as penas e medidas de segurança a serem aplicadas. ${ }^{13}$

Observa-se que o autor é claro em afirmar que "pensa-se logo em fatos humanos classificados como delitos" e aponta que o pensamento quanto a retribuição por esse crime é pensada como "prisão", através de uma interpretação histórica.

Continuando, quanto ao Crime, segundo lições tradicionais de Direito Penal, (teoria do crime tripartido), um fato típico, antijurídico e culpável, (para os finalistas é toda ação típica e antijurídica, ficando a culpa para a aplicação da pena), onde a ação ou omissão deve se ajustar a uma conduta previamente determinada em Lei.

Mais uma vez, Francisco de Assis Toledo, mostrado o lado rígido do Direito Penal, informa que:

O crime, além de fenômeno social, é um episódio da vida de uma pessoa humana. Não pode ser dela destacado e isolado. Não pode ser reproduzido em laboratório, para estudo. Não pode ser decomposto em partes distintas. Nem se apresenta, no mundo da realidade, como puro conceito, de modo sempre idêntico, estereotipado. Cada crime tem sua história, a sua individualidade; não há dois que possam ser reputados perfeitamente iguais. Mas não se faz ciência do particular. E, conforme vimos inicialmente, o Direito Penal não é uma ciência ou mera catalogação de fatos, quer ser uma ciência pratica. Para tanto, a nossa disciplina, enquanto ciência, não pode prescindir de teorizar a respeito do agir humano, ora submetendo-o a métodos analíticos, simplificadores ou generalizadores, ora sujeitando-o a amputações, por abstração, para a elaboração de conceitos, esquemas lógicos, institutos e sistemas mais ou menos cerrados. ${ }^{14}$

\footnotetext{
12 SALLES JUNIOR, 2009, p. 12. Apud.

13 TOLEDO, 2008, p. 1.

14 TOLEDO, 2008, p. 79.
} 
Partindo dessa premissa para justificar o que se segue, com a edição da Lei 9.605/98, passou-se ter uma proteção jurídica específica de diversos bens de caráter ambiental com definição de tipos penais específicos, porém, essa Lei criou um verdadeiro subsistema de proteção jurídico-penal para o meio ambiente, com princípios e pressupostos específicos para essa proteção, conforme explica Ana Paula Fernandes Nogueira da Cruz ${ }^{15}$.

A norma em conceito não se limitou a descrever tipos penais para a tutela de bens ambientais. Ela criou um sistema de proteção jurídica com princípios e pressupostos próprios, consubstanciado nas normas de caráter geral descritas nos artigos $2^{\circ}$ a 28 , verdadeira Parte Geral da Lei de Crimes Ambientais.

Essa criação sistemática, devido a necessidade de se tutelar o meio ambiente de forma efetiva, para atingir os preceitos do art. 225 da Constituição Federal de 1988, contemplou a responsabilização, porém manteve a culpabilidade tradicional ao Direito Penal. Assim, partindo-se de uma teoria tradicional de crime, a conduta que se adéqua a norma descrita na Lei 9.605/98, (fato típico), contrariando-a, (antijuridicidade), para se tornar crime, sujeita a sanção penal, necessita ser também culpável, ou seja, sob a ótica do Direito Penal essa conduta deve ser injustificada, conforme continua explicando Ana Paula Fernandes Nogueira da $\mathrm{Cruz}^{16}$.

Assim, enquanto os demais ramos do Direito para a responsabilização do agente basta que a conduta seja antijurídica, ao Direito Penal vai importar se essa conduta encontra justificativa sob a ótica penal, em outras palavras, se tal conduta é culpável.

O que se quer dizer é que a responsabilidade penal é subjetiva, mesmo no direito ambiental, devido a sua característica individualizadora, pois todos os ramos do direito comungam da antijuridicidade e da ilicitude levando a responsabilização, conforme será visto, mas a culpabilidade é requisito para uma condenação criminal, nullum crimen sine culpa, (princípio da culpabilidade), ou seja, a observação da culpabilidade como princípio fundamental do Direito Penal está a se negar a responsabilidade penal objetiva, não podendo se basear exclusivamente nos fatos praticados e no resultado para uma responsabilização na seara criminal, já que condutas que não se materializam, (falta de prova), ou se exaurem sem dolo ou culpa não podem ser punidas, pois assim expõe Nilo Batista, em trecho retirado do livro Teorias da Culpabilidade e Teoria do Erro ${ }^{17}$.

O princípio da culpabilidade impõe a subjetividade da responsabilidade penal. Não cabe, em Direito Penal, uma responsabilidade objetiva, derivada

\footnotetext{
${ }^{15}$ MARCHESAN, 2013, p. 27.

${ }^{16}$ MARCHESAN, 2013, p. 28.

${ }^{17}$ RODRIGUES, 2010, p. 29. Apud.
} 
somente da associação causal entre a conduta e um resultado de lesão ou perigo para um bem jurídico. É indispensável a culpabilidade. A responsabilidade penal é sempre subjetiva.

A manutenção da culpabilidade, ou seja, a conformação do Direito Penal Ambiental com a dogmática Penalista se faz obrigatória para se evitar a contrariedade da Constituição Federal e a criação de normas autoritárias, descaracterizando o Estado Democrático de Direito. Tanto é assim que a Lei 9.605/98, em seu art. $2^{\circ}$ informa essa necessidade.

Art. $2^{\circ}$ Quem, de qualquer forma, concorre para a prática dos crimes previstos nesta Lei, incide nas penas a estes cominadas, na medida da sua culpabilidade, bem como o diretor, o administrador, o membro de conselho e de órgão técnico, o auditor, o gerente, o preposto ou mandatário de pessoa jurídica, que, sabendo da conduta criminosa de outrem, deixar de impedir a sua prática, quando podia agir para evitá-la. grifo nosso.

Assim, por tudo até aqui exposto, a responsabilização da pessoa física é de maior aceitabilidade, havendo a dificuldade de aceitação da responsabilização da pessoa jurídica não só pela pena restritiva de liberdade, pois é certo que as penas não se consubstanciam unicamente em prisão através de uma visão mais moderna, mas pela impossibilidade de se vislumbrar o dolo, sem falar nos argumentos do autor Francisco de Assis Toledo expostas acima.

Superando-se esse pré-conceito, acatando-se a Lei e a jurisprudência que criminalizam a pessoa jurídica, ainda há a pendência de ser a responsabilização penal subjetiva, o que não pode ser modificado pelos motivos já expostos, fato que de certo pode ser empecilho para restauração do meio ambiente danificado e um meio ambiente nos moldes Constitucionais, começando-se a se delinear a relação entre o crime ambiental e a responsabilidade civil. A existência de um dano ao meio ambiente é fato que contraria os objetivos Constitucionais. A restauração ou a reparação é fator indispensável para se atingir um meio ambiente ecologicamente equilibrado essencial a qualidade de vida e, o Direito Penal, em muitos casos não será capaz de dar a solução, ou até mesmo penalizar, o responsável ou possível responsável, principalmente se o responsável for somente possível, in dubio pro reo, o que se dificulta ainda mais quando se trata de pessoa jurídica.

Certo é que a Constituição da República Federativa do Brasil de 1988 aponta, principalmente em seu artigo 225, uma necessidade de se tutelar o meio ambiente, com as finalidades lá expostas, e para Robert Alexy o Direito possui dupla natureza, compreendendo tanto uma dimensão real e como uma dimensão ideal, ${ }^{18}$ e "A idéia geral desse sistema é a institucionalização da razão". ${ }^{19}$

\footnotetext{
18 "The real and the ideal dimension of lew".

${ }^{19}$ ALEXY, 2014, p. 129-130.
} 


\section{A APLICAÇÃO DA RESPONSABILIDADE CIVIL NOS CASOS DE DANO AMBIENTAL}

Conforme já explanado, a responsabilização no Direito Penal é subjetiva, enquanto em outros ramos do direito como o Consumidor, Administrativo e Cível são objetivas, por força de Lei, podendo ser verificado no art. 14 da Lei 8.078/90, (responsabilidade do fornecedor); no $\S 6^{\circ}$ do art. 37 da Constituição Federal de 1988, (responsabilidade administrativa); no $\S 1^{\circ}$ do art. 14 da Lei 6.938/81, (responsabilidade ambiental).

Nos seguintes termos informa o art. 14 da Lei 8.078/90:

Art. 14. O fornecedor de serviços responde, independentemente da existência de culpa, pela reparação dos danos causados aos consumidores por defeitos relativos à prestação dos serviços, bem como por informações insuficientes ou inadequadas sobre sua fruição e riscos.

Se extrai do $\S 6^{\circ}$ do art. 37 da Constituição Federal de 1988 o que se segue:

$\S 6^{\circ}$ - As pessoas jurídicas de direito público e as de direito privado prestadoras de serviços públicos responderão pelos danos que seus agentes, nessa qualidade, causarem a terceiros, assegurado o direito de regresso contra o responsável nos casos de dolo ou culpa.

E no que tange ao Direito Ambiental, assim expõe o $\S 1^{\circ}$ do art. 14 da Lei 6.938/81:

$\S 1^{\circ}$ Sem obstar a aplicação das penalidades previstas neste artigo, é o poluidor obrigado, independentemente da existência de culpa, a indenizar ou reparar os danos causados ao meio ambiente e a terceiros, afetados por sua atividade. O Ministério Público da União e dos Estados terá legitimidade para propor ação de responsabilidade civil e criminal, por danos causados ao meio ambiente.

Sendo o último apresentado, Direito Ambiental, o de maior relevância para o presente estudo, devidamente recepcionado pelo art. 225 da Constituição Federal de 1988, já que instituída antes da promulgação desta, tratando da questão ambiental, trouxe a figura do poluidor pagador, do princípio da prevenção e da precaução, e por isso tendo como pressuposto a existência de uma atividade de risco para o meio ambiente, pressupondo portanto o dano ou risco de dano e o nexo de causalidade entre a atividade e o resultado, efetivo ou potencial.

Observa-se que a responsabilidade pelo dano independe de dolo ou culpa, bastando a conduta e o resultado para caracterizar a responsabilização, ou seja, "o liame entre a ação ou omissão e o dano for identificado, a responsabilização estará caracterizada." ${ }^{20}$

${ }^{20}$ STEINGLEDER, 2011, p. 171. 
Certo é que nem sempre foi assim, pois a responsabilização no Direito Civil, em todos os casos, era subjetiva, necessitando da ação ou omissão, dano, nexo de causalidade e culpa ou dolo para a responsabilização do agente.

Conforme já exposto, o art. 225 da Constituição Federal de 1988 trouxe a proteção ambiental por ser este meio ambiente essencial a sadia qualidade de vida e, como explica Karina Marcos Bedran e Elizabeth Mayer, revista veredas, sempre houve dificuldade de se demonstrar culpa em se tratando de Direito Ambiental. Um exemplo disso é o caso de várias indústrias alocadas às margens de um rio jogando dejetos nele e o poluindo, quem é o responsável?

Assim, devido a importância do direito tutelado, o meio ambiente, direito difuso (bem de uso comum do povo), essencial a sadia qualidade de vida, - Brasil passou a utilizar a responsabilização objetiva para dirimir esses problemas, forma de responsabilização que não está especificado no art. 225, mas, como informado anteriormente, foi recepcionada pela Constituição, já que explicito na Lei de Política Nacional do Meio Ambiente, Lei 6.938/81, no $\S 1^{\circ}$ do seu art. 14. "A teoria objetiva prescinde de demonstração de culpa, bastando a comprovação do dano e do nexo causal" ${ }^{11}$

Sem entrar na seara da origem da responsabilidade objetiva, essa vem sendo utilizada pelo Brasil, em seus tribunais através da observância de duas teorias, a saber, Teoria do Risco Crido e Teoria do Risco Integral.

A Teoria do Risco Criado se baseia no conceito de sociedade de risco contemporânea, sociedade reflexiva de Beck ${ }^{22}$, onde as atividades desenvolvidas podem levar à responsabilização caso sua conduta cause danos. Rui Stoco define a teoria do risco criado da seguinte forma:

A teoria do risco criado é aquela na qual o agente responde em razão do risco ou perigo que a atividade exercida apresenta, ou seja, aquele que, em razão de sua atividade ou profissão cria um perigo ou expõe alguém ao risco de dano. Nesta teoria a responsabilidade não está conectada a um proveito ou lucro, mas apenas à conseqüência da atividade em geral, de sorte que a idéia do risco passa a conectar-se a qualquer atividade humana que seja potencialmente danosa para outros, como na previsão do art. 927 do $\mathrm{CC} .^{23}$

Certo é que a Teoria do Risco Criado admite excludentes de ilicitude.

A Teoria do risco integral por sua vez não admite excludentes de ilicitude. Isso se dá pelo fato da dificuldade na aferição do nexo causal. Por isso os tribunais brasileiros vêm utilizando o critério de imputação do risco integral no dano ambiental. Tal entendimento é utilizado por Édis Milaré, Antônio Herman

\footnotetext{
${ }^{21}$ STEINGLEDER, 2011, p. 48.

22 BECK, 2011.

${ }^{23}$ STOCO, 2007, p. 161.
} 
Benjamin, Jorge Alex Nunes Athia, Sérgio Cavalieri Filho, Nelson Nery Júnior, Sérgio Ferraz, dentre outros. ${ }^{24}$

No seguinte sentido é o entendimento de Sergio Ferraz:

Não deve haver uma grande preocupação em relacionar a atividade do agente com o prejuízo. Basta que, potencialmente, a atividade do agente possa acarretar prejuízo ecológico para que se inverta imediatamente 0 ônus da prova, para que imediatamente se produza a presunção de responsabilidade, reservando, portanto, para o eventual acionado o ônus de procurar excluir sua imputação. ${ }^{25}$

Nelson Nery Júnior informa o seguinte:

A indenização é devida independentemente de culpa e, mais ainda, pela simples razão de existir a atividade da qual adveio o prejuízo: o titular da atividade assume todos os riscos dela oriundos. Dessa maneira, não se operam, como causas excludentes de responsabilidade, o caso fortuito ou força maior. Ainda que a indústria tenha tomado todas as precauções para evitar acidentes danosos ao meio ambiente, se, por exemplo, explode um reator controlador da emissão de agentes químicos poluidores (caso fortuito), subsiste o dever de indenizar. Do mesmo modo, se por um fato da natureza ocorrer o derramamento de substância tóxica existente no depósito de uma indústria (força maior), pelo simples fato de existir a atividade há o dever de indenizar. ${ }^{26}$

A demonstração na prática dessa aplicabilidade se apresenta pelo julgado do STJ, o qual vem aplicando a Teoria do Risco Integral em seus julgados devido a relevância do tema:

RESPONSABILIDADE CIVIL POR DANO AMBIENTAL. RECURSO ESPECIAL REPRESENTATIVO DE CONTROVÉRSIA. ART. 543-C DO CPC. DANOS DECORRENTES DO ROMPIMENTO DE BARRAGEM. ACIDENTE AMBIENTAL OCORRIDO, EM JANEIRO DE 2007, NOS MUNICÍPIOS DE MIRAÍ E MURIAÉ, ESTADO DE MINAS GERAIS. TEORIA DO RISCO INTEGRAL. NEXO DE CAUSALIDADE.

1. Para fins do art. 543-C do Código de Processo Civil: a) a responsabilidade por dano ambiental é objetiva, informada pela teoria do risco integral, sendo o nexo de causalidade o fator aglutinante que permite que o risco se integre na unidade do ato, sendo descabida a invocação, pela empresa responsável pelo dano ambiental, de excludentes de responsabilidade civil para afastar sua obrigação de indenizar; ${ }^{27}$

\footnotetext{
${ }^{24}$ BEDRAN, 2013, p. 58.

${ }^{25}$ BEDRAN, 2013, p. 58.

${ }^{26}$ BEDRAN, 2013, p. 59.

${ }^{27}$ REsp 1374284/MG.
} 
Certo é que toda a questão discutida tem como único propósito a proteção ambiental, recaindo sobre conhecimentos transdiciplinares, conforme explica José Rubens Morato Leite: ${ }^{28}$

Mencione-se que a temática incide sobre o campo de conhecimento transdiciplinar, evocando contribuição de todas as áreas de saber. A tarefa da elaboração de mecanismos que visam à proteção ambiental diz respeito, portanto, a uma discussão transdisciplinar, e tal atitude acarreta imensa dificuldade.

Em sua configuração, o dano ambiental tem um perfil multidimensional, atingindo concomitantemente o bem jurídico ambiental e outros interesses jurídicos. O sistema jurídico brasileiro protege o bem jurídico ambiental com finalidade dúplice: (a) no que diz respeito à proteção e capacidade funcional do ecossistema; e (b) visando a conservar a sua capacidade de aproveitamento humano.

Estas características, entre outras, do dano ambiental suscitam questões complexas nos meios jurídicos que visam à proteção do meio ambiente, posto que este foge de longe da versão tradicional de dano.

Assim, ainda que o direito não consiga solucionar todos os problemas provenientes das questões ambientais, também pela dificuldade na união trasdiciplinar, a responsabilidade civil objetiva, principalmente com o viés da teoria do risco integral, parece dar uma resposta mais condizente com a previsão constitucional, trazendo uma forma com possibilidade de maior acerto na reparação ou na restauração, necessária para a legitimação do Estado, pois conforme Habermas, "a fé na legalidade das ordens prescritas e na competência dos que foram chamados a exercer o poder não se confunde simplesmente com a fé na tradição ou carisma, uma vez que ela tem a ver com a racionalidade que habita na forma do direito..." 29

\section{RELAÇÃO ENTRE O CRIME AMBIENTAL E A RESPONSABILIDADE CIVIL}

Tendo em vista o já discutido, parece não existir uma relação direta entre o crime ambiental e a responsabilidade civil, o que se repete, parece, pois apesar da interdependência das searas administrativa, cível e penal apontada anteriormente, ou seja, apesar da previsão legal de possibilidade de aplicação de pena, sanção e reparação, o Direito Penal se entrelaça aos demais ramos do direito no que tange ao meio ambiente para se atingir o fim maior que é a conquista de meio ambiente equilibrado (sustentabilidade ambiental) essencial à qualidade de vida. Na prática, no que tange ao meio ambiente, (Direito Ambiental), a aplicação do Direito Penal seria inviável sem o apoio administrativo, já que, v.g, a descoberta da infração penal se dá pela atuação do órgão

\footnotetext{
${ }^{28}$ LEITE, 2014, p. 21.

${ }^{29}$ HABERMAS, 2003, p. 193.
} 
administrativo, IBAMA, ou por descumprimento de requisito que deixaria de caracterizar-se como crime, (licença).

Também se relaciona com o Direito Civil, pois as penas aplicadas no Direito Penal a pessoa jurídica se baseiam em multa, restrição de direito e prestação de serviço, (art. 21 da Lei 9.605/98), de forma subjetiva, ou seja, com a constatação do crime, ou suposto crime, punível ou não, tendo em vista ser a responsabilidade penal subjetiva, haverá a reparação cível já que essa responsabilidade é objetiva, (restauração ou reparação). Observa-se que o $\S 1^{\circ}$ do art. 14 da Lei 6.938/81, confere ao Ministério Público o poder de propor ações de responsabilidade tanto Criminal, poder já conferido pela Constituição Federal, como Civil, garantindo uma maior efetividade na reparação do dano causado ao meio ambiente.

\section{CONCLUSÃo.}

Dentro de suas diversas divisões temáticas (com valor apenas didático) cabe ao Direito Ambiental a justa regulação entre as relações dos homens na apropriação da natureza. No entanto, há uma constante tensão entre apropriação e conservação dos recursos naturais, pois a quantidade e forma de sua apropriação devem ser estudadas, pois são os motes para a fixação do verdadeiro limite ao compromisso pela manutenção das bases produtivas.

A princípio, conforme aponta Leite, "o perfil inicial do Estado, com características relevantes no que concerne a uma equidade ambiental, desenha-se certamente com um sistema compatível de responsabilização." ${ }^{30}$ :

Não há Estado Democrático de Direito se não é oferecida a possibilidade de aplicar toda espécie de sanção àquele que ameace ou lese o meio ambiente. Viu-se, anteriormente, que princípios, como a precaução, atuação preventiva e cooperação podem oferecer subsídios importantes à edificação de um Estado mais justo do ponto de vista ambiental, mas deve-se observar que aqueles, isoladamente, não funcionam. ${ }^{31}$

Certo é que para a prática da garantia ao meio ambiente, ou seja, para a efetivação dos preceitos apresentados pela Constituição Federal, (art. 225), o Direito Penal, após a consumação do crime ambiental e consequentemente a realização do dano ambiental, sozinho, não tem meios para garantir essa efetivação, graças à perquirição indispensável da subjetividade do agente. Observa-se que o Direito Penal necessita, comumente, do Direito Administrativo para ser colocado em prática e, sem dúvida, a efetiva proteção e equilíbrio de um meio ambiente sustentável necessita de todos os ramos do Direito, além de outras disciplinas, como mecanismo para atingir seu objetivo, exposto no art. 225 da Constituição Federal.

\footnotetext{
${ }^{30}$ LEITE, 2014, p. 63.

${ }^{31}$ LEITE, 2014, p. 63 e 64.
} 
Assim, conclui-se que com a prática de um Crime Ambiental, tendo o Ministério Público autonomia para proposição da ação civil ex delicto, a prática de um crime ambiental resultará também em uma responsabilização civil, como forma de se tentar a restauração, reparação ou recomposição do Meio Ambiente, não bastando à sanção penal para garantir o equilíbrio ecológico e fazer valer os preceitos constitucionalmente previstos.

\section{REFERÊNCIAS}

ALEXY, Robert. Princípios Formais e outros Aspectos da Teoria Discursiva do Direito. 1. ed., Rio de Janeiro: Forense, 2014.

BALEEIRO NETO; GONÇALVES. Medidas Despenalizadoras e Proteção Penal do Meio Ambiente. Disponível em: http://www. publicadireito.com.br/artigos/?cod=1a47e 38c424a51ab. Acesso em: 16 abr. 2015.

BECK, Ulrich. Sociedade de Risco Rumo a uma Outra Modernidade. 2. ed., São Paulo: Editora 34, 2011.

BEDRAN, Karina Marcos; MAYER, Elizabeth. A Responsabilidade Civil por Danos Ambientais no Direito Brasileiro e Comparado: Teoria do Risco Criado versus Teoria do Risco Integral. Revista Veredas do Direito, Belo Horizonte, v. 10 no 19 p. 45-88, jan./jun. de 2013. Disponível em: <http://mww.domhelder.edu.br/revista/index.php/veredas/ article/viewFile/271/339>. Acesso em: 10 abr. 2015.

BRASIL. Constituição (1988). Constituição da República Federativa do Brasil. Brasília, DF: Senado, 1988.

FERRAJOLI, Luigi. Direito e Razão: Teoria do Garantismo Penal. 3. ed., São Paulo: Revista dos Tribunais, 2010.

FIORILLO, Celso Antonio Pacheco. Curso de Direito Ambiental Brasileiro. 15. ed., São Paulo: Saraiva, 2014.

HABERMAS, Jurgen. Direito e Democracia entre Facticidade e Validade - volume II. 2. ed., Rio de Janeiro: Tempo Brasileiro, 2003.

HIRECHE, Gamil Foppel El. A Função da Pena na Visão de Claus Roxin. Rio de Janeiro: Forense, 2004.

LEITE, José Rubens Morato. Dano Ambiental do Individual ao Coletivo Extrapatrimonial. Teoria e Prática. 6. ed., São Paulo: Revista dos Tribunais, 2014.

MACHADO, Paulo Affonso Leme. Direito Ambiental Brasileiro. 33. ed., São Paulo: Malheiros, 2015.

MARCÃO, Renato. Crimes Ambientais. 2. ed., São Paulo: Saraiva, 2013.

MARCHESAN, Ana Maria Moreira. Crimes Ambientais: Comentários à Lei 9.605/98. Porto Alegre: Livraria do Advogado, 2013.

PRADO, Luiz Regis; DOTTI, René Ariel. Responsabilidade Penal da Pessoa Jurídica. 3. ed., São Paulo: Revista dos Tribunais, 2011.

RODRIGUES, Cristiano. Teorias da Culpabilidade e Teoria do Erro. 3. ed., Rio de Janeiro: Forense, 2010.

RODRIGUES, Marcelo Abelha. Processo Civil Ambiental. 3. ed., São Paulo: Revista dos Tribunais, 2011. 
SALLES JUNIOR, Romeu de Almeida. Curso Completo de Direito Penal: Parte Geral e Parte Especial. 10. ed., Belo Horizonte: Del Rey, 2009.

SILVA, José Afonso. Direito Ambiental Constitucional. 10. ed., São Paulo: Malheiros, 2013.

STEINGLEDER, Annelise Monteiro. Responsabilidade Civil Ambiental: As dimensões do Dano Ambiental no Direito Brasileiro. 2. ed., Porto Alegre: Livraria do Advogado, 2011.

STOCO, Rui. Tratado de Responsabilidade Civil: doutrina e jurisprudência. 7. ed., São Paulo: Revista dos Tribunais, 2007.

TOLEDO, Francisco de Assis. Princípios Básicos de Direito Penal. 5. ed., (14ª tiragem). São Paulo: Saraiva, 2008. 